\title{
界面活性剂水溶液の衝突噴流
}

\section{Impinging jet of surfactant solutions}

\author{
ONguyen Anh Tuan（首都大院） 正 水沼博 （首都大）
}

\begin{abstract}
H. Mizunuma, Tokyo Metropolitan University, 1-1, Minami-Osawa, Hachioji, Tokyo 192-0397, Japan N. A. Tuan, Tokyo Metropolitan University, 1-1, Minami-Osawa, Hachioji, Tokyo 192-0397, Japan
\end{abstract}

The surfactant solutions can significantly reduce turbulent friction drag, which is useful for increasing flow rate that helps to save energy of pump. In recently, application of impinging jet for cooling electronic devices gets a large attractiveness. Using surfactant fluid is also promising in the closed-loop applications by implementing single phase impinging jet. In this work, the laminar flow simulation was performed to the $2 \mathrm{D}$ axi-symmetric submerged and confined impinging jet for surfactant solution. The numerical investigation was compared with the result of flow visualization.

Key Words: Impinging Jet, Surfactant Solution, Simulation, Visualization

\section{Introduction}

Fluid flow and heat transfer characteristics of an impinging jet are of high interest in engineering because impinging jets are widely used in industrial cooling or heating process. A significant amount of research on the characteristics of impinging jet has been published. The researches include theoretical analyses, experiments, and numerical simulations. Most of the numerical investigations have focused on the impinging jets for Newtonian fluids. As well-known, surfactant fluids can significantly reduce turbulent frictional drag. The phenomenon is useful for increasing flow rate that helps to save the energy of a pump. Using surfactant fluid is promising in the closed-loop applications by implementing single phase impinging jet. However, the study on the impinging jet with surfactant fluids is still limited.

In this work, the simulation was performed to the $2 \mathrm{D}$ axi-symmetric submerged and confined impinging jet for surfactant fluids. The numerical investigation was compared with the result of flow visualization.

\section{Governing equations and numerical methods}

The configuration considered is a jet impinging on a flat plate. The nozzle diameter $D$ was $10 \mathrm{~mm}$. The distance between jet exit and the impinging wall $\mathrm{H}$ was equal to $\mathrm{D}$. The computation grid was resolved in the way that both the upstream and downstream flow around the nozzle and expanded far to side of the impinging jet $(80 \mathrm{~mm})$ to provide realistic exit conditions. The working liquids were the surfactant solution $500 \mathrm{ppm}$ with ten times higher molecular concentration of the counter-ion, and the surfactant solution 1800ppm with equimolar counter-ion. The Reynolds number based on water viscosity is 1000 . The viscous model of the surfactant solutions fit the Power Law model with parameters $K=0.00197, n=1$ for the surfactant $500 \mathrm{ppmx} 10$, and $\mathrm{K}=0.73$, n $=0.2$ for the surfactant $1800 \mathrm{ppmx} 1$. The set of governing equations was integrated using the finite element method. All computations were performed with the commercial finite element CFD code POLYFLOW 3.10 .

\section{Results and discussions}

Velocity - The velocity contour map is shown in the Fig. 1 for the surfactant solution of 500ppmx10. The flow field of an impinging jet consists of three distinctive flow regions, namely a free jet region, a stagnation region, and a wall jet region. The free jet region develops from the exit of the nozzle. The stagnation region where the strong interaction of the jet with the surface produces a deceleration as it approaches the target wall. The flow then changes its direction and starts accelerating away from the stagnation point. Downstream from the stagnation, the wall jet region begins to decelerate along the direction parallel to the target wall.

Recirculation pattern - The presence of the confined wall creates a recirculation. The toroid appears at the edge of the nozzle exit, then develops and moves radially outward and closer to the impinging wall as the velocity increases along with time. This is the unique feature of the confined and submerged impinging jet.

Pressure - The pressure gradually increases when surfactant solution leaves from the nozzle exit and reaches a maximum at the target wall. The pressure then decreases toward the exit of impinging jet (Fig.3).

Comparison of results between the numerical simulation and the visualization method

The Figure 4 shows a visualization of boundary layer thickness in the wall jet region of impinging jet of water when the Reynolds number $\mathrm{Re}$ is 1000 . The boundary layer thickness gradually increases when coming from region around the nozzle to side of the impinging jet. The flow of surfactant solution $500 \mathrm{ppmx} 10$ at the same Reynolds number $(\mathrm{Re}=1000)$ also presents the tendency of boundary layer to be similar to that of water. However, the boundary layer thickness of this surfactant solution is larger than that of water. This phenomenon becomes more clearly when coming far to side of the impinging jet (Fig.5). The numerical simulation also provides with the similar results.

Visualizations of the surfactant 1800ppmx 1 flow at different Reynolds numbers $(\operatorname{Re}=1000,3000$, and 8000$)$ are shown in the Fig.6. Due to strongly elastic property of this surfactant, its flow field is unstable. The larger the Reynolds number, the more unstable the flow. At the Reynolds number $R e=1000$, the flow region is limited (Fig.6a). When the Reynolds number reaches to approx.3000, the flow region is expanded (Fig.6b).

\section{Conclusions}

Flow field of the submerged and confined impinging jet for surfactant solutions $500 \mathrm{ppmx} 10$ and $1800 \mathrm{pmx} 1$ was investigated. The numerical investigation was compared with the result of flow visualization. Visualizations of the surfactant $1800 \mathrm{ppmx} 1$ at different Reynolds numbers were also shown. 


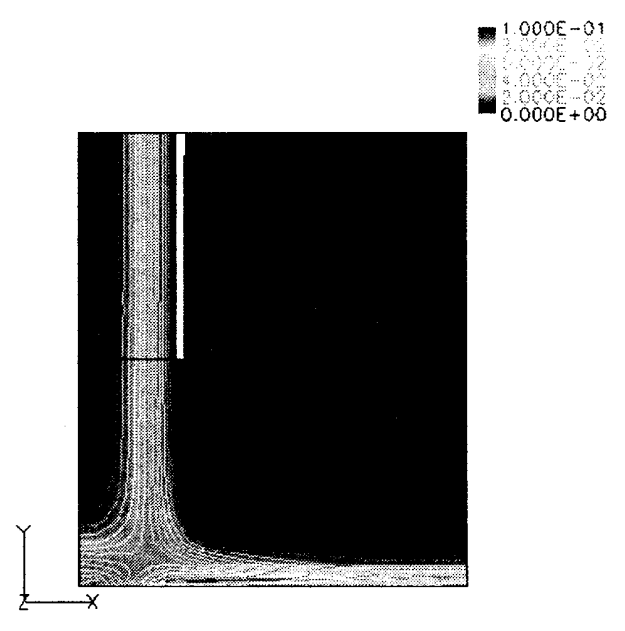

Fig.1 Contour map of velocity, surfactant 500ppmx10

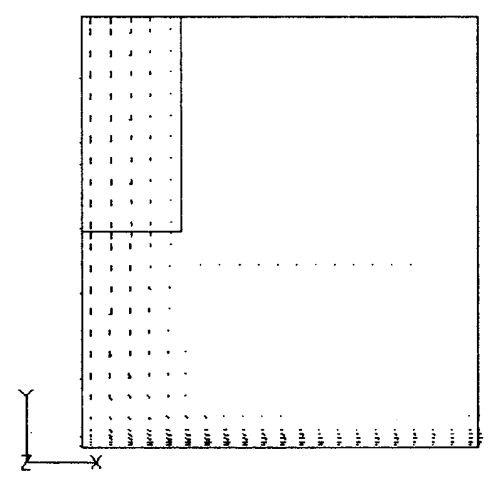

Fig.2 Vector map, surfactant 500ppmx 10

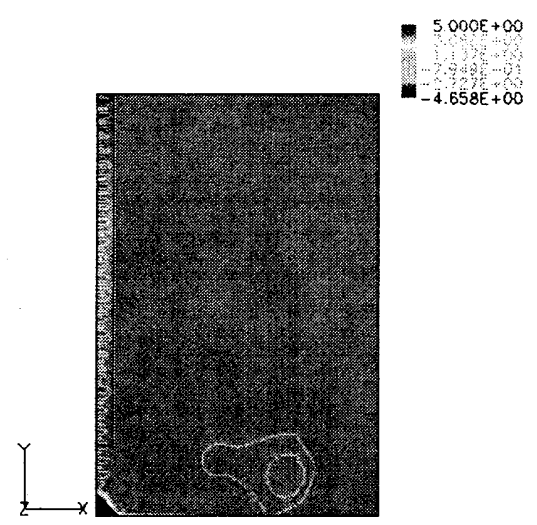

Fig.3 Pressure map, surfactant 500ppmx 10

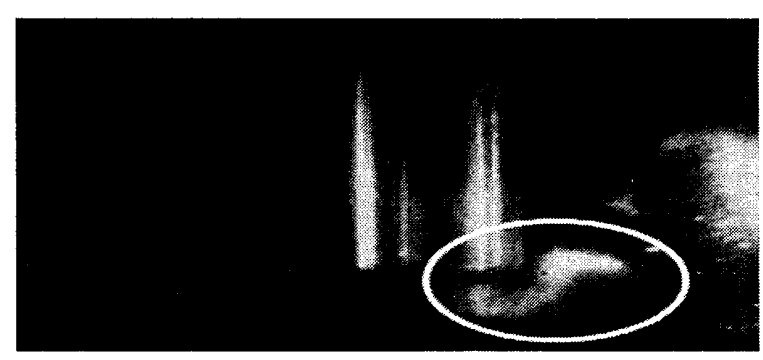

(a)

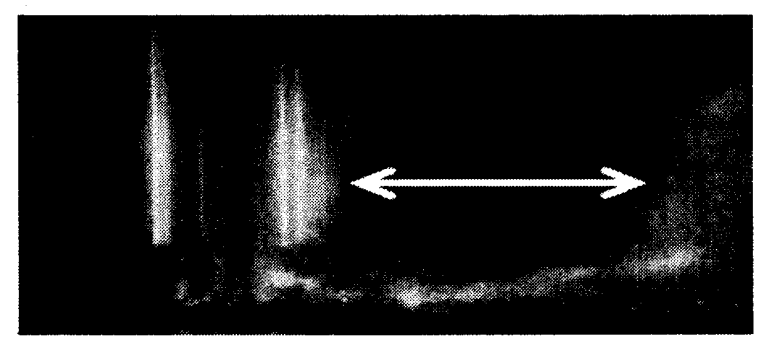

(b)

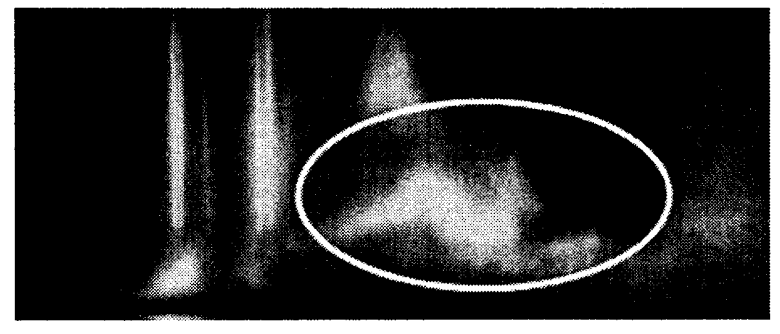

(c)

Fig.6 Change of flow pattern of surfactant 1800ppm x 1 (a) $\operatorname{Re}=1000$, (b) $\operatorname{Re}=3000$, (c) $\operatorname{Re}=8000$

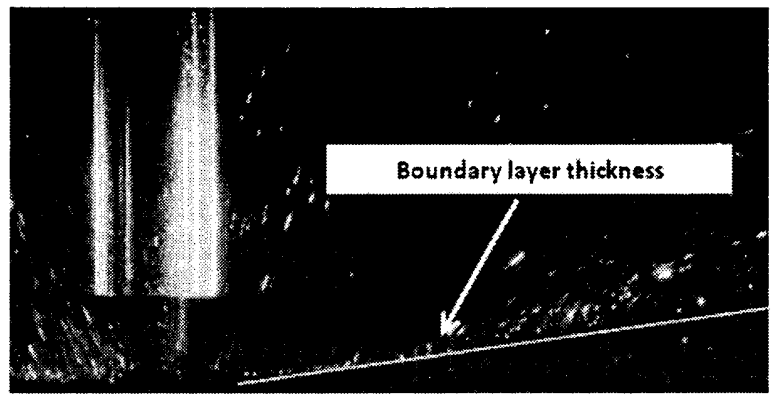

Fig.5 Boundary layer thickness of surfactant 500ppm x 10, $\operatorname{Re}=1000$

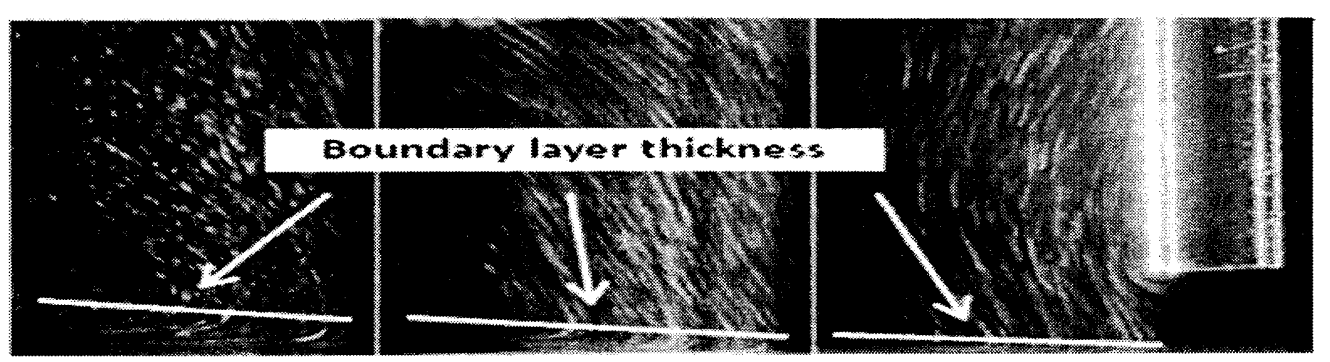

Fig.4 Boundary layer thickness of water, $\operatorname{Re}=1000$ 